NBER WORKING PAPER SERIES

\title{
COMOVEMENT IN CITIES
}

John Shea

Working Paper 5304

\section{NATIONAL BUREAU OF ECONOMIC RESEARCH 1050 Massachusetts Avenue \\ Cambridge, MA 02138 \\ October 1995}

Forthcoming, Carnegie-Rochester Conference Series on Public Policy, volume 44, Spring 1996. This paper is a revised version of a paper presented at the Carnegie-Rochester Conference on Public Policy in April 1995 in Rochester, NY. The author thanks Bill Miracky for providing data, and Allan Meltzer, Valerie Ramey, and other conference participants for helpful suggestions. All errors are mine. Research support from the National Science Foundation is acknowledged. This paper is part of NBER's research program in Monetary Economics. Any opinions expressed are those of the author and not those of the National Bureau of Economic Research.

() 1995 by John Shea. All rights reserved. Short sections of text, not to exceed two paragraphs, may be quoted without explicit permission provided that full credit, including $\odot$ notice, is given to the source. 


\title{
COMOVEMENT IN CITIES
}

\begin{abstract}
Recent research has shown that industries that locate together in space also move together over the business cycle, and that this correspondence between spatial and temporal comovement is important to aggregate volatility. This paper asks whether this correspondence is due to local common shocks or to local spillovers. I examine interindustry comovements within seven large US cities, and find strong evidence for local spillovers. I estimate that local spillovers explain roughly one-third of manufacturing employment volatility at the city level. Local spillovers do not appear to result from transport costs and locally traded goods.
\end{abstract}

\section{John Shea}

Department of Economics

University of Wisconsin 1180 Observatory Drive Madison, WI 53706 and NBER 


\section{INTRODUCTION}

An important fact about business cycles in the postwar US is that different industries exhibit positive short-run comovement. For instance, over the period 1978-1987, the average pairwise correlation of annual employment growth among the twenty SIC two-digit manufacturing industries is 0.542 ; for the 125 roughly three-digit manufacturing industries listed in the appendix, the average pairwise correlation is 0.382. Similar evidence is presented in Long and Plosser (1987), Murphy, Shleifer and Vishny (1989), and Cooper and Haltiwanger (1990).

Interindustry comovement is an interesting fact in and of itself; however, it is also crucial to aggregate volatility. For instance, let $y$ denote the growth rate of aggregate manufacturing employment. We can approximate $y$ as a weighted average of employment growth in $M$ disaggregated manufacturing sectors, as follows:

$$
y_{t} \cong \sum_{i=1}^{M} \operatorname{SHARE}_{i} y_{i t},
$$

where SHARE $_{i}$ is industry i's long-run average share of total manufacturing employment. Let SHARE denote a 1-by-M vector of long-run industry employment shares, and let $\Psi$ denote the $M-b y-M$ variance-covariance matrix of industry-level employment. Then from (1), the variance of aggregate manufacturing employment is approximately

$$
\text { SHARE * } \Psi^{*} \text { SHARE', }
$$

which in turn can be decomposed into a "diagonals" term due to the diagonal elements of $\Psi$, and a "comovement" term due to the off-diagonal elements of $\Psi$. For the US over the period 1978-1987, the actual standard deviation of annual aggregate manufacturing employment growth is 4.08 percent. For 20 two-digit manufacturing industries, the 
standard deviation implied by equation (2) is 4.27 percent when $\Psi$ is set equal to the observed interindustry variance-covariance matrix over the sample period. When only the diagonal elements of $\Psi$ are considered, the standard deviation implied by (2) is 1.51 percent; when only the of $f$-diagonals are included, the standard deviation is 3.99 percent. At the two-digit level, comovement thus accounts for 87.5 percent of the variance of aggregate manufacturing empioyment growth. For the 125 three-digit industries listed in the appendix, the standard deviation implied by (2) is 4.16 percent using observed $\Psi, 0.86$ percent using the diagonals of $\Psi$, and 4.07 percent using the off-diagonals of $\Psi$; at the three-digit level, comovement thus accounts for 95.8 percent of aggregate volatility. This evidence suggests that understanding the causes of cyclical comovement is in some sense tantamount to understanding the causes of aggregate volatility itself.

Some comovement presumably results from the direct effects of aggregate shocks, such as oil prices and monetary policy, that affect many industries simultaneously. However, comovement may also result from interindustry linkages or complementarities that propagate shocks from one sector to another; plausible sources of complementarity that have been proposed in the literature include factor demand linkages (Long and Plosser (1983)), aggregate demand linkages (Startz (1989)), thick market externalities (Diamond (1982)) and external economies of scale (Baxter and King (1991)). Of course, complementarities and aggregate shocks can work together; for instance, money may directly affect only the auto industry, but shocks to autos may be transmitted to steel through input-output linkages or some other complementarity.

In parallel work (Shea (1995)), I examine the role of complementarities in generating short-run comovement among three-digit 
manufacturing industries at the national level in the postwar US. Among other things, I find evidence of a link between the interindustry patterns of spatial location and temporal comovement: industries that locate in the same cities tend to comove over the business cycle at the national level. This link is economically as well as statistically significant. For instance, I estimate that the component of short-run comovement associated with spatial clustering is responsible for between 15 and 36 percent of aggregate employment volatility in manufacturing, depending on how I treat aggregate shocks in the estimation; moreover, this spatial factor is more important to both comovement and aggregate volatility than input-output linkages.

To see the link between spatial clustering and short-run comovement, consider the following empirical example. Let CORREMP ${ }_{\text {ik }}$ denote the temporal correlation of employment growth between industries $i$ and $k$. Let CORRCIT $i k$ denote the spatial correlation between industries $i$ and $k$, defined as follows:

$$
\operatorname{CORRCIT}_{i k}=\frac{\sum_{j=1}^{M} \operatorname{SHARE}_{j i} \text { SHARE }_{j k}}{\left[\sum_{j=1}^{M}\left(\operatorname{SHARE}_{j i}^{2}\right)\right]^{1 / 2}\left[\sum_{j=1}^{M}\left(\operatorname{SHARE}_{j k}^{2}\right)\right]}
$$

where SHARE $_{j i}$ is the long-run average share of city $j$ in industry i's employment, and $M$ is the number of cities used to measure CORRCIT. CORRCIT measures the extent to which two industries concentrate their employment in the same cities; the numerator is the dot product of the industries' vectors of employment shares by city, while the denominator normalizes by each industry's spatial concentration.

I measure CORREMP using annual national-level data over the period 1978-1987 for the 125 three-digit manufacturing industries listed in the 
appendix; the resulting 125 -by-125 correlation matrix has 7750 upper diagonal elements. I measure CORRCIT using data from the Census Bureau's annual publication County Business Patterns for the 100 largest US metropolitan areas as of 1970, where the SHARE terms are computed averaging employment over the period 1977-1987; the data are described more fully below. An OLS regression of CORREMP on a constant and CORRCIT yields the following results:

$$
\text { CORREMP }_{i k}=\underset{(0.008)}{0.182}+\underset{(0.014)}{0.400 \text { CORRCIT }_{i k}}+\varepsilon \text {, }
$$

where OLS standard errors are in parentheses. ${ }^{1}$ Equation suggests that temporal comovement and spatial clustering are positively related; the coefficient on CORRCIT is positive and highly significant. Furthermore, the R-squared in equation (4) is 0.09 , suggesting that spatial correlation can explain an economically important amount of variation in the degree of short-run temporal comovement across pairs of national industries. Of course, part of this relationship may be due to input-output linkages, which may cause linked industries both to comove over the cycle and to locate in the same cities to minimize transportation costs; however, in Shea (1995) I show that spatial clustering and temporal comovement are closely linked even after controlling for input-output linkages.

The goal of this paper is to explore why industries that locate in the same cities tend to comove over the business cycle. As I discuss further below, there are three generic reasons why spatial and temporal comovement might be linked. First, there might be city-specific shocks, such as weather or local tax policies, that are important sources of short-run volatility. Under local common shocks, industries clustered together in space will tend to comove through time at the national level 
by virtue of experiencing a similar mix of local shocks. Second, there might be symmetric local activity spillovers, in which increases in overall city activity raise optimal output for each city-industry. Under symmetric local spillovers, shocks to industry i will propagate via local activity to other industries located in the same cities as $\mathrm{i}$, so that again industries clustered together in space will comove over time at the national level. Third, there might be asymmetric local spillovers, in which optimal activity of industry $i$ in city $j$ depends on a weighted average of local activity in other sectors, with the degree of synergy varying across industry pairs. Under asymmetric local spillovers, industry pairs with strong links will comove over time at the national level, and will also optimally cluster in the same cities to take maximum advantage of their synergy.

As the above discussion suggests, distinguishing the three generic stories using national data alone is likely to be difficult, since the stories have broadly similar implications for industry comovement at the national level. Fortunately, it turns out that the three stories have sharply different implications for the pattern of industry comovement within cities. Local common shocks do not imply any relationship a priori between the pattern of comovement within a particular city and the pattern of industry location in that or other cities. Symmetric local spillovers imply that the pattern of comovement within a particular city should depend on the vector of steady-state industry activity shares within that city, but not on the pattern of industry location in other cities. Finally, asymmetric local spillovers imply that the pattern of comovement within a particular city should resemble the pattern of industry location in other cities. Thus, one can distinguish between the three generic stories using data on fluctuations 
at the city-industry level.

My empirical work examines employment fluctuations over the period 1978-1987 for 387 disaggregated manufacturing city-industries, taken from seven large US metropolitan areas. Following Shea (1995), I assume that comovement within a city depends on the covariance matrix of underlying city-industry shocks and on a propagation matrix that governs how shocks are transmitted across local sectors. These two matrices in turn depend on observable measures of potential interindustry complementarity, such as measures of input-output linkages or spatial correlation, and on parameters governing the strength of different linkage mechanisms. By putting sufficient restrictions on the covariance matrix of shocks, I can estimate the complementarity parameters using maximum likelihood, and assess whether particular linkages enter significantly and with the right sign. I can also assess the economic importance of complementarities by computing their contribution to the variance of city-level employment.

The rest of this paper proceeds as follows. The next section presents a simple model of an economy composed of many industries located in many cities. I use this model to illustrate the implications of local common shocks, symmetric local spillovers, and asymmetric local spillovers for the pattern of interindustry comovement, both at the national level and within cities. The third section describes the data and presents empirical estimates of a baseline model nesting the implications of local common shocks and local spillovers. I find that both symmetric and asymmetric local spillovers exist, and that local spillovers account on average for roughly one-third of a sample city's manufacturing employment volatility. The fourth section asks whether local spillovers are a consequence of limited intercity tradeability of 
certain goods due to high transport costs, using data from the 1977 Census of Transportation to measure the tradeability of different goods. I find that transport costs do not appear to be responsible for local spillovers. The fifth section concludes.

This paper contributes to a growing literature using data at the local level to examine questions of broad macroeconomic interest. Rauch (1993) and Ciccone and Hall (1993) use local wage and income data to test for agglomeration economies in production. Head, Ries and Swenson (1994) test for agglomeration economies by examining the location choices of Japanese companies investing in the US. Glaeser et al (1992), Miracky (1992) and Henderson (1994) use city-industry data to examine the importance of local spillovers to long-run growth. Topel (1986), Blanchard and Katz (1992) and Lettau (1994) examine the short-run adjustment of local labor markets to shocks. My work differs from most of this previous literature in that I focus on the causes of short-run comovement and volatlity, rather than on the existence of agglomeration economies, defined here as economies of scale resulting from industry localization. I examine the magnitude and direction of short-run links among local industries, but for the most part I do not attempt to address whether interindustry linkages are due to economies of scale or to demand linkages.

The issues addressed in this paper are important to macroeconomists for two reasons. First, as indicated above, the component of short-run comovement associated with interindustry spatial clustering appears to be important to aggregate employment volatility at the national level. Understanding why industries that cluster together in space also comove over time would thus further our understanding of aggregate business cycles. Second, short-run fluctuations at the city level are themselves 
an interesting topic for macroeconomics. The existence of local spillovers makes it more likely that particular cities or regions will experience large idiosyncratic booms and busts unrelated to the pattern of activity at the national level.

\section{A SIMPLE MODEL OF LOCAL FLUCTUATIONS}

This section presents a model in which a large number of goods are produced in a large number of spatially distinct locations. I use the model to illustrate the implications for comovement of local common shocks, symmetric local spillovers, and asymmetric local spillovers. I show that all three stories can generate a relationship between spatial clustering and temporal comovement at the national level. However, these stories have different implications for the pattern of interindustry comovement in cities, implying that one can distinguish among them by examining fluctations at the local level.

The Model

There is a representative consumer whose utility is linear in the consumption of $\mathrm{N}$ final goods and in hours worked:

$$
U_{t}=\sum_{i=1}^{N} C_{i t}-L_{t}
$$

Each final good, in turn, can be produced in $M$ spatially distinct cities. Assume that each city produces differentiated varieties of each good, which are imperfect substitutes in utility. Thus,

$$
C_{i t}=\sum_{j=1}^{M} \log \left(Q_{i j t}\right) \text {, }
$$

where $Q_{i j t}$ denotes production of good $i$ in city $j$ at time $t$. Assume that each city-industry's output depends on labor and on a 
technology shift variable $\lambda_{i j t}$, taken as exogenous by all agents:

$$
Q_{i j t}=\lambda_{i j t}{ }^{*} L_{i j t} .
$$

It is easy to show that the competitive equilibrium of this economy satisfies $L_{i j t}=1$ for all $(i, j, t)$; thus, (7) simplifies to

$$
Q_{i j t}=\lambda_{i j t} .
$$

The implications of the model for comovement will thus depend entirely on the specification of the technology shift parameter $\lambda$.

\section{Case One: Local Common Shocks}

In this case, technology is specifled as follows:

$$
\lambda_{i j t}=\exp \left(u_{j t}\right) * \exp \left(v_{i t}\right) * \exp \left(w_{i j}\right)
$$

Technology depends on three mean-zero random components: $u_{j t}$, which varies over cities and time and but not industries; ${ }_{i t}$, which varies across industries and time but not cities; and $w_{i j}$, which varies across cities and industries but not time. One can think of $v$ as an industry-specific technology shock, $u$ as a city-specific technology shock, and $w$ as a Ricardian parameter reflecting long-run locational attributes that give certain cities a comparative advantage in hosting particular industries.

Let $Q_{i t}$ denote industry i's output at the national level at time $t$, defined as the sum of $Q_{i j t}$ over the $M$ cities. Then a log-linear approximation yields

$$
\begin{aligned}
& \log \left(Q_{i t}\right) \equiv q_{i t} \cong \text { Constant }+v_{i t}+\sum_{j=1}^{M} \operatorname{SHARE}_{j i} u_{j t}, \quad \text { (10) } \\
& \text { where } \operatorname{SHARE}_{j i} \text { is city j's steady-state share of industry i's }
\end{aligned}
$$


national output, which in turn satisfies

$$
\operatorname{SHARE}_{j i}=\exp \left(w_{i j}\right), \sum_{z=1}^{M} \exp \left(w_{i z}\right),
$$

so that the distribution of industry i's activity across cities in steady-state depends only on the comparative advantage parameters $w$.

Equation (10) implies that the pattern of interindustry comovement at the national level depends on the steady-state distribution of industries in space. For instance, suppose the v's are uncorrelated across industries and the $u^{\prime}$ 's are uncorrelated across cities with unit variance. Then for any pair of national industries $i$ and $k$, we have

$$
\operatorname{Cov}\left(q_{i t}, q_{k t}\right)=\sum_{j=1}^{M}\left(\operatorname{SHARE}_{j i} * \operatorname{SHARE}_{j k}\right)
$$

which increases as the spatial correlation between $i$ and $k$ ises. In this model, industries that locate in the same cities tend to comove over time at the national level because they experience a similar mix of local common shocks. Notice that there are no interindustry synergies in this model; industries that locate together do so only because their comparative advantage profiles across cities are similar.

Notice, too, that in this model location affects short-run comovement only at the national level. From (8) and (9), output in city-industry ij satisfies

$$
q_{i j t} \equiv \log \left(Q_{i j t}\right)=\text { Constant }+u_{j t}+v_{i t} \text {, }
$$

so that short-run comovement between city-industries $i j$ and $k j$ depends only on the covariances of the underlying cyclical shocks: for instance, if the $v$ 's are uncorrelated across industries, the covariance between any pair of local industries will be a constant, equal to the variance of $u$. Under local common shocks, then, there is no reason a 
priori to expect the pattern of comovement within a particular city to be positively related to the steady-state pattern of industry location in that or in other cities. Indeed, if there is any prior presumption, it is in the opposite direction: the labor market pooling hypothesis, discussed by Marshall (1949) and Krugman (1991), suggests that industries with negatively correlated cyclical shocks should optimally cluster in the same cities, to provide stable local labor demand and hence to reduce wage premia required to compensate workers for unemployment risk. ${ }^{2}$

Case Two: Symmetric Local Activity Spillovers

In this case, technology is specified as follows:

$$
\lambda_{i j t}=\exp \left(w_{i j}\right) * \exp \left(v_{i t}\right) *\left(Q_{j t}\right)^{\beta}
$$

where again $w$ is a comparative advantage parameter, $v$ is an industry technology shock, $\beta$ is restricted to lie in $(0,1)$, and

$$
Q_{j t}=\sum_{i=1}^{N} Q_{i j t}
$$

is overall output in city $j$ at time $t$. According to (14), an increase in overall city activity symmetrically increases optimal activity in each city-industry. Assuming that agents take $\lambda$ as given, a log-linear approximation to the competitive equilibrium yields

$$
q_{i j t} \cong \text { Constant }+v_{i t}+\mu \sum_{k=1}^{N} \operatorname{SIZE}_{k j} v_{k t},
$$

where $\mu$ equals $(\beta / 1-\beta)$ and $\operatorname{SIZE}_{\mathbf{k}_{j}}$ equals industry $\mathrm{k}^{\prime}$ s steady-state share of city j's total output. From (16), fluctuations in city-industry if depend on i's technology shock and on a weighted average of technology shocks in all other industries. The weights are 
proportional to city-industry size; shocks to city-industry $\mathrm{kj}$ have a larger impact on city-industry $i j$ the more important is industry $k$ to city j's overall activity. Intuitively, shocks to big city-industries have a large impact on local activity, and thus are more likely to be transmitted to other local industries than shocks to small city-industries. One can show in turn that

$$
\operatorname{SIZE} E_{k j}=\exp \left(w_{k j}\right), \sum_{z=1}^{N} \exp \left(w_{z j}\right)
$$

so that, as in Case One, the steady-state distribution of industry activity across cities depends only on comparative advantage.

Aggregating to the national industry level, one can show that

$$
q_{i t} \cong \text { Constant }+v_{i t}+\mu \sum_{k=1}^{N} C_{i k} v_{k t} \text {, }
$$

where

$$
\operatorname{CITY}_{i k}=\sum_{j=1}^{M} \operatorname{SHARE}_{j i} * \operatorname{SIZE}_{k j} \text {, }
$$

and where SHARE $_{j i}$ is city j's steady-state share of industry i's national output, which as before satisfies (11). According to (18), fluctuations in national industry $i$ depend on technology shocks to all industries. The effect of a shock to industry $k$ on industry $i$ is proportional to CITY $i k$, which equals the average over $M$ cities of $k$ 's steady-state share of local activity, weighted by each city's steady-state share of i's activity. CITY $i k$ thus measures the extent to which industry $i$ is concentrated in cities where industry $k$ is important. If CITY ${ }_{i k}$ is large, then shocks to $k$ have a large impact on those cities where $i$ is located, and thus propagate to i via the local activity spillover.

As with local common shocks, symmetric local activity spillovers 
imply that the pattern of interindustry comovement at the national level depends on the pattern of industry location. Comovement between industries $i$ and $k$ increases with CITY $i k$, which increases both in $k$ 's size and in the degree to which $\mathrm{i}$ and $\mathrm{k}$ cluster spatially. However, under symmetric spillovers, spatial clustering has no effect on comovement in cities. From (16), comovement within a particular city depends on the vector of steady-state industry activity shares for that city, but not on the industry location pattern in other cities.

Case Three: Asymmetric Local Spillovers

In this case, technology is specified as follows:

$$
\lambda_{i j t}=\exp \left(v_{i t}\right) * \exp \left(w_{i j}\right) * \prod_{k=1}^{N}\left(Q_{k j t}\right)^{\beta i k},
$$

where again $v$ is an industry technology shock and $w$ is a comparative advantage parameter. According to (20), productivity in city-industry $i j$ depends on the output of other local industries, indexed by $k$. The spillover parameters $\beta_{i k}$ are constant over time and over cities, but vary among industry pairs; intuitively, some industry pairs have stronger synergies than others. Let $\beta$ denote the $\mathrm{N}$-by-N matrix of spillover parameters, let I denote an $\mathrm{N}$-by-N identity matrix, and assume that the matrix $F=(I-\beta)^{-1}$ exists. Then the competitive equilibrium of this economy satisfies

$$
q_{i j t}=\bar{q}_{i j}+\sum_{k=1}^{N} F_{i k} v_{k t} \text {. }
$$

where $F_{i k}$ is an element of the matrix $F$, and where $\bar{q}_{i j}$ is city-industry ij's steady-state output, which in turn satisfies

$$
\bar{q}_{i j}=\sum_{k=1}^{N} F_{i k} w_{k j} .
$$


From (21), fluctuations in city-industry ij depend on technology shocks in all industries. The effect of a shock to industry $k$ on city-industry ij depends on $F_{i k}$, which in turn depends on the strength of direct and indirect synergies linking the two industries. From (22), meanwhile, steady-state activity in city-industry ij depends on the comparative advantage parameters for all local industries, weighted by the synergy parameters $F_{i k}$. Notice that in this case, unlike the two previous cases, comparative advantage alone does not determine the steady-state pattern of industry location; holding comparative advantage constant, industries with strong synergies will optimally cluster together in space to take maximum advantage of local spillovers.

Aggregating to the national industry level, one can show that

$$
q_{i t}=\text { Constant }+\sum_{k=1}^{N} F_{i k} v_{k t} \text {. }
$$

This model implies that the pattern of short-run comovement among national industries should resemble the interindustry pattern of location. From (23), industries with strong synergies tend to comove over the business cycle; from (22), industries with strong synergies also tend to locate together. At the national level, then, the implications of asymmetric local spillovers are similar to those of local common shocks or symmetric local spillovers. However. asymmetric spillovers have different implications for local comovement. From (21), comovement in cities is driven by the same synergies that generate both national comovement and spatial clustering. Therefore, the pattern of comovement within a particular city should resemble the pattern of clustering in other cities. Notice that, in contrast to the previous two cases, the relationship between industry location and short-run comovement in this case is not causal. Geographic clustering does not 
by itself affect the pattern of interindustry comovement locally or nationally. Instead, the pattern of industry location reflects the underlying pattern of interindustry synergies; and these synergies, in turn, affect the pattern of interindustry comovement.

\section{EMPIRICAL EVIDENCE}

The next two sections examine the pattern of comovement among 387 disaggregated manufacturing city-industries, taken from seven large US metropolitan areas. This section tests the implications of the three generic models described above, and finds evidence for both symmetric and asymmetric local spillovers. The next section then attempts to learn more about the exact mechanism generating these local spillovers, by examining the role of limited intercity tradeability of goods with high transport costs.

The CBP Data

Distinguishing among the three models presented above requires data on short-run fluctuations at the city-industry level. The only such data for the US is the Census Bureau's annual publication County Business Patterns (hereafter the CBP), which provides employment by disaggregated industry for every state and county in the United States. The CBP covers all sectors of the economy except for farms, railroads, government, and government-run enterprises such as the postal service and public utilities. The data used in this paper cover the period 1977-1987; after log first-differencing, I have 10 observations on employment growth for each county-industry. ${ }^{3}$

The main limitation of the CBP is that by federal law it cannot publish information that would disclose the operations of an individual 
establishment. In practice, this means that the CBP cannot provide exact employment figures for county-industries consisting of a small number of establishments, or dominated by a single large employer. In such cases, the CBP reports a range for county-industry employment (e.g. 0-19, 20-99, 100-249, and so on), along with the number of establishments in each range.

While one can make plausible imputations for these nondisclosures, I do not want to use imputed data to analyze short-run fluctuations. 4 My sample selection procedure is thus as follows. For a given city, I begin with employment data for 125 disaggregated manufacturing industries for every county belonging to the city's consolidated metropolitan statistical area (CMSA). The industries are primarily at the SIC three-digit level, and are listed in the appendix. For each city-industry, I create two time series: EMP1, which sums employment over all counties that have exact figures available for each year in the period 1977-1987; and EMP2, which sums over all counties, using imputed values for nondisclosures where necessary. If the eleven-year average of EMP1 is at least 50 percent of the eleven-year average of EMP2, then I set employment growth for the city-industry equal to the growth rate of EMP1, and include the city-industry in the sample; otherwise, I exclude the city-industry from the sample. Obviously, my procedure is likely to select more industries from large cities than from small cities, since small cities are more likely to experience nondisclosures. I thus limit my search to the seven largest US metropolitan areas as of 1970: New York, Los Angeles, Chicago, Philadelphia, Detroit, San Francisco and Boston.

Table 1 presents descriptive information for the sample. The second and third columns report the number of sample industries for each 
city ("Sectors") and the fraction of each city's manufacturing employment accounted for by the sample industries ("Coverage"). 5 Los Angeles, for instance, has data available for 102 out of 125 possible city-industries, covering 98.3 percent of city employment; the excellent coverage is not surprising given that Los Angeles County is the largest urban county in the US. Philadelphia, on the other hand, consists of several smaller counties, and thus has data for only 30 industries, covering 42.5 percent of city employment. In all, my sample includes 387 city-industries, listed in the appendix.

The remaining columns of Table 1 present evidence on the importance of interindustry comovement for employment volatility at the city level. The fourth column ("Average Corr") shows the average within-city pairwise correlation among the sample industries. The average correlation ranges from 0.079 for Philadelphia to 0.224 for New York. The fifth column ("Actual") reports the standard deviation of annual employment growth for the city-level aggregate defined by summing employment over sample industries. The sixth column ("Implied") reports the standard deviation for this aggregate implied by the approximation

$$
\text { SHARE * } \Psi * \text { SHARE }^{\prime} \text {, }
$$

where SHARE is a vector showing each city-industry's long-run average share of city employment within the sample, while $\Psi$ is the observed covariance matrix for city-industry employment growth. ${ }^{6}$ The similarity between the fifth and sixth columns suggests that the approximation (24) works well in my sample. Finally, the last column shows the fraction of the implied variance of city-level employment due to off-diagonal elements of $\Psi$. Interindustry comovement accounts for between 72 and 89 percent of aggregate employment volatility for each city. Overall, Table 1 suggests that the sample cities display positive 
short-run interindustry comovement, and that this comovement is important to city-level employment volatility.

Empirical Model

I now present the empirical framework used in this paper. Suppose for now that one has time-series data on employment growth for $\mathrm{N}$ disaggregated industries in one city (say, Chicago); I generalize to multiple cities below. I assume fluctuations in Chicago obey

$$
y_{t}=\mu+G * a_{t}+A * \varepsilon_{t}+v_{t}
$$

where $y_{t}$ is an $\mathrm{N}-\mathrm{by}-1$ vector of Chicago's employment growth rates at time $t ; \mu$ is an $N$-by-1 vector of constants; $a_{t}$ is a P-by-1 vector of observable macroeconomic shocks; $G$ is an N-by-P vector governing the response of city-industries to macroeconomic shocks; $\varepsilon_{t}$ is an $N-b y-1$ vector of unobservable mean-zero city-industry shocks, assumed mutually uncorrelated and orthogonal to $a_{t}$, with $\mathrm{N}-\mathrm{by}-\mathrm{N}$ diagonal covariance matrix $\Sigma ; A$ is an $N-b y-N$ matrix governing how the $\varepsilon$ shocks are propagated across local sectors; and $v_{t}$ is an N-by-1 vector of unobservable city-industry shocks, assumed orthogonal to $a_{t}$ and to $\varepsilon_{t}$, with (possibly non-diagonal) covariance matrix $\Omega$. Equation (25) implies that the covariance matrix for $y_{t}$ can be written as

$$
\Psi=G * \phi * G^{\prime}+A * \Sigma * A^{\prime}+\Omega,
$$

where $\phi$ is the P-by-P covariance matrix of aggregate shocks. Equation (26) decomposes interindustry comovement within Chicago into three sources. First, comovement can result from observable aggregate shocks, provided the matrices $\mathrm{G}$ and $\phi$ are nonzero. Second, comovement can result from the propagation of idiosyncratic shocks across sectors, provided the matrix $A$ is nondiagonal. Finally, comovement can result 
from nondiagonality of $\Omega$. In practice, including the matrix $\Omega$ in (25) allows me to incorporate potential determinants of local comovement that would not fit easily into a framework in which comovement was driven solely by observable aggregate shocks or propagation of unobservable local shocks through the A matrix.

As in Shea (1995), I assume that $a_{t}$ consists of two elements: the growth rate of the real Producer Price Index for fuels and power (OIL) and the spread between the commercial paper and Treasury-Bill interest rates (SPREAD), intended to proxy for monetary policy. Meanwhile, I model both $\Omega$ and A as functions of observable measures of potential interindustry linkage. To distinguish among the three generic models outlined above, I want to allow the pattern of comovement in Chicago to depend potentially on local common shocks, on steady-state industry activity shares in Chicago, and on the pattern of industry location in other cities. I also want to control for other potential sources of local comovement. In Shea (1995), I find that input-output linkages are important to comovement at the national level; it seems reasonable to assume that such linkages could affect comovement in cities as well. My baseline specification for $A$ and $\Omega$ is thus as follows:

$$
\begin{aligned}
& A=\mathrm{ID}+\beta_{1} * \operatorname{COST}+\beta_{2} * \mathrm{DEM}+\beta_{3} * \mathrm{SIZE} \\
& \Omega=\beta_{4} * \mathrm{CITY}+\alpha_{\mathrm{CH}} * \mathrm{COMMON},
\end{aligned}
$$

where ID is an $\mathrm{N}$-by-N identity matrix; COST, DEM, SIZE, CITY and COMMON are $\mathrm{N}-\mathrm{by}-\mathrm{N}$ matrices; and $\alpha_{\mathrm{CH}}$ and the $\beta^{\prime}$ 's are scalar parameters. Following Shea (1995), I set the diagonal elements of COST, DEM, SIZE, CITY and COMMON equal to zero; this normalizes the own-effect of a city-industry shock to one. The matrices COST, DEM and SIZE thus affect only how shocks are propagated across sectors, while CITY and COMMON 
affect only the cross-industry covariances of the $v$ shocks; the variances of $\varepsilon$ shocks are determined by the matrix $\Sigma$, which has elements $\sigma_{1}$ through $\sigma_{\mathrm{N}}$

COST and DEM control for the effects of factor demand linkages on local comovement. The $[\mathrm{i}, \mathrm{k}]$ element of COST equals the total dollar requirement of good $k$ per dollar produced of good $i$, incorporating direct and indirect input-output linkages, while the $[i, k]$ element of DEM equals the fraction of demand for good i ultimately embodied in final purchases of good $k$. As shown in the simple input-output model of Shea (1995), COST[i,k] measures the extent to which shocks propagate from an upstream input supplier $k$ to a downstream user $i$, while DEM[i,k] measures the extent to which shocks propagate from downstream user $k$ to upstream supplier $i$; below, I sometimes refer to propagation from suppliers to users as a "cost linkage", and propagation in the reverse direction as a "demand linkage". COST and DEM are measured at the national level using 1977 input-output data, as described in the appendix; unfortunately, city-level input-output data do not exist in the US.

SIZE allows the pattern of local comovement to depend on symmetric local activity spillovers. The $[i, k]$ element of SIZE equals industry k's long-run average employment in Chicago, divided by long-run average manufacturing employment in Chicago. 7 Following the discussion above, symmetric local activity spillovers imply that $\beta_{3}$ should be positive; shocks to large Chicago-industries should have stronger effects on Chicago's overall activity, and thus stronger effects on other local sectors, than shocks to small Chicago-industries.

CITY allows the pattern of local comovement to depend on asymmetric local spillovers. The $[i, k]$ element of CITY is equal to 


$$
\sum_{j=1}^{M} \operatorname{SHARE}_{j i} * \operatorname{SHARE}_{j k} \text {, }
$$

where $M$ is the number of cities over which CITY is measured, and SHARE $_{j i}$ is city j's long-run average share of industry i's national employment. CITY measures the degree to which industries locate together in space. Following the discussion above, asymmetric local spillovers imply that $\beta_{4}$ should be positive; industries that cluster spatially presumably have strong synergies, and these strong synergies should in turn cause local comovement. I measure CITY using data for the largest 100 US cities as of 1970 . To make my test of asymmetric spillovers as clean as possible, I exclude the seven sample cities when computing SHARE and CITY; thus, I test whether comovement in the sample cities depends on the pattern of industry location in other cities. ${ }^{8}$

Finally, COMMON is a matrix of ones. I include COMMON to allow for local common shocks. My specification follows Case One of the model outlined in the previous section; recall that if industry-specific shocks are jointly orthogonal, and the local shock affects all sectors equally, then the covariance between industries $i$ and $k$ implied by equation (13) is simply a constant, equal to the variance of the local shock. Thus, if local common shocks are important to comovement in Chicago, we would expect to find $\alpha_{\mathrm{CH}}$ significantly positive. Admittedly, this method of incorporating local shocks is crude; it would be preferable to control for local shocks directly using city-specific time-series data on weather conditions, local taxes, and other observable local factors. Unfortunately, I did not have such data at my disposal for this project.

I estimate my model using a two-step procedure. I first estimate $\mu$ and the matrix $G$ by regressing employment growth on a constant, OIL and 
SPREAD industry-by-industry; these regressions fit best when I lag OIL and SPREAD one year. These estimates are consistent under the assumption that $a_{t}$ is orthogonal to $\varepsilon_{t}$. I then use the residuals from these regressions, which I denote $\tilde{y}_{t}$, to estimate the $\beta, \alpha$ and $\sigma$ parameters using maximum likelihood. Assuming that $\varepsilon$ is normal, the $\log$ likelihood for T observations on Chicago's $\mathrm{N}$ industries is

$$
-(T * N) / 2-(T / 2) * \log |\tilde{\Psi}|-(1 / 2) \sum_{t=1}^{T}\left(\tilde{y}_{t}^{\prime} \tilde{\Psi}^{-1} \tilde{y}_{t}\right),
$$

where $\tilde{\Psi}=A * \Sigma * A^{\prime}+\Omega$ is the interindustry covariance matrix for $\tilde{y}$ implied by (25).

To this point, I have discussed estimation using data for only one city. I now discuss the case of multiple cities. One possible approach would be to specify a model such as (25) for the vector of all industries from all cities, so that $y_{t}$ would have length

$$
P=\sum_{j=1}^{J} N_{j}
$$

where $J$ is the number of cities in the sample and $N_{j}$ is the number of industries available for city $j$. I do not pursue this approach for two reasons. First, to implement this approach properly I would need to model the comovements of industries across cities as well as within cities; in other words, I would need to allow the matrices $A$ and $\Omega$ to be non-block diagonal. The pattern of comovement among cities is a worthy topic for future research, but it is beyond the scope of this paper. Second, at a more practical level, this approach would require inverting a P-by-P matrix at least twice during each iteration of the maximum likelihood algorithm, which for large $P$ would entail considerable computation time.

Therefore, I assume instead that fluctuations within each city can 
be described by equations (25) and (27)-(28), where for city $j$ the vector $y_{t}$ has dimension $N_{j}$. The log likelihood for each city's $\tilde{y}_{t}$ residuals is given by (30); the tailoring of COST, DEM, SIZE and CITY to each city is described in the appendix. I assume that the parameters $\beta_{1}$ through $\beta_{4}$ are identical across cities, while the local common shock variance $\alpha$ and the elements of $\Sigma$ can vary from city to city. Since I have 387 city-industries, I must estimate 398 parameters: the 387 elements of $\Sigma$, the seven local shock variances $\alpha$, and the complementarity parameters $\beta_{1}$ through $\beta_{4}$. I estimate these parameters by maximizing the sum of the city-level log likelihoods, as detailed in the appendix; since the $\sigma$ and $\alpha$ parameters can be interpreted as variances, I restrict their estimates to be positive.

\section{Parameter Estimates}

Table 2 presents results from estimating the baseline specification. Standard errors are in parentheses, and are estimated by numerical computation of the Hessian matrix at the maximum likelihood estimates. Estimates of $\Sigma$ are available from the author.

Results are as follows. First, input-output demand and cost linkages are both statistically significant to comovement in cities. The coefficients on COST and DEM are smaller than those estimated in Shea (1995) using national data, suggesting that input-output linkages do not bind as strongly at the local level as at the national level. 9 This is not surprising, given that goods presumably flow more easily within countries than across countries. A shock to Detroit auto plants, for instance, is likely to spill over to windshield manufacturers in Ohio and Indiana, but is less likely to spill over to Canada; the link between autos and windshields is thus likely to be stronger for the US 
as a whole than for Detroit.

Second, I find evidence for both symmetric and asymmetric local spillovers. The coefficient on SIZE is positive and significant, implying that shocks to large city-industries propagate more strongly to other local sectors than shocks to small city-industries, consistent with spillovers in the overall level of local activity. The coefficient on CITY is also positive and significant, implying that the pattern of comovement within sample cities resembles the pattern of spatial clustering in nonsample cities, consistent with asymmetric spillovers that give certain pairs of industries an incentive to move together in both space and time.

Third, I find little evidence for local common shocks. The estimated local shock variances are miniscule for four out of the seven sample cities, and would have been negative had I not restricted them to be positive. The local shock variances for Los Angeles, Detroit and Boston are larger, but statistically insignificant.

Goodness of Fit

Tables 3 and 4 present evidence on the estimated model's ability to fit the volatility and comovement features of the data. In Table 3 , the third column ("Implied Volatility") shows the standard deviation of city-level employment implied by the approximation in equation (24), where the covariance matrix $\Psi$ is set either to the observed covariance matrix in the original data (in rows marked "Data"), or to the fitted covariance matrix including the effects of aggregate shocks, calculated by evaluating equation (26) at the empirical estimates (in rows marked "Fitted"). The fourth and fifth columns report the mean and standard deviation of the within-city pairwise correlations implied by either the 
observed or fitted $\Psi$, while the last column reports the correlation between the observed and fitted pairwise correlations. Table 4 is similar to Table 3, except that rows marked "Data" now refer to the the residuals from projecting the data on the aggregate shocks, while rows marked "Fitted" now refer to the fitted model excluding the estimated effects of aggregate shocks. In both tables, I report statistics for each city, as well as the average of each statistic across cities.

The main result of Table 3 is that the fitted model including the effects of aggregate shocks does a reasonably good job matching the volatility and comovement features of the data. On average, the fitted model implies an annual standard deviation of city employment growth of 5.03 percent, compared to 5.26 percent using the covariance matrix found in the data. The model also explains cross-city differences in employment volatility reasonably well, with San Francisco being a notable exception. On average, the model predicts a mean pairwise correlation within cities of 0.163 , slightly higher than the true value of 0.151 . The predicted and observed pairwise correlations have a correlation across pairs of city-industries of 0.602 , suggesting that the fitted model does a good job explaining why some pairs of city-industries comove more strongly than others.

Turning to Table 4, we find that removing aggregate shocks from both the data and the fitted model noticeably reduces the goodness of fit. On the positive side, the model still fits the volatility and mean correlation features of the data reasonably well, although again the model does a poor job accounting for employment volatility in San Francisco. On the negative side, the average correlation between the pairwise correlations implied by the data and the model falls to 0.211 , so that removing aggregate shocks substantially reduces the model's 
ability to explain why some pairs of city-industries comove more strongly than others. Furthermore, the standard deviation across city-industry pairs of the fitted pairwise correlations is now far below the corresponding standard deviation in the data. The model without aggregate shocks thus does a poor job explaining the magnitude of variation in the degree of comovement found in the data.

Upon closer examination, one reason for this last failure is that the model without aggregate shocks cannot explain the fact that some city-industry pairs exhibit negative short-run comovement. Averaging over the seven sample cities, 34 percent of within-city pairwise correlations are negative in the raw data; this fraction rises to 39 percent for the residuals from projecting the data on aggregate shocks. The fitted model including the effects of aggregate shocks generates negative pairwise correlations 18 percent of the time; however, the fitted model excluding aggregate shocks generates no negative correlations among city-industries, which follows directly from the fact that all four $\beta$ parameters have positive point estimates, while the variance parameters $\alpha$ and $\Sigma$ are restricted to be positive. Future research should attempt to identify reasons why industries might interact negatively over the business cycle, and add variables measuring the potential strength of such negative interaction to the empirical specification used in this paper and in Shea (1995).

Variance Decomposition

The estimates reported in Table 2 suggest that symmetric and asymmetric spillovers are statistically significant sources of local comovement. This does not necessarily mean, however, that local spillovers are economically important. Table 5 addresses the economic 
importance of local spillovers by decomposing the fitted model's implications for city-level employment volatility into components due to aggregate shocks, local spillovers, and other factors.

The first row of Table 5 shows the fraction of the fitted model's implied city employment variance due to aggregate shocks. The numerator of this fraction is calculated using the variance approximation in equation (24), setting $\Psi$ equal to $\hat{G} * \hat{\phi} * \hat{G}^{\prime}$, where $\hat{G}$ is the estimated impact of aggregate shocks on city-industries and $\hat{\phi}$ is the estimated covariance matrix of aggregate shocks. The second row shows the fraction of fitted variance due to shock variances alone; this is computed using equation (24), setting $\Psi$ equal to $\hat{\Sigma}$. The third row shows the fraction of volatility due to cost linkages; this is computed by defining $\hat{A}_{\text {COST }}$ as ID $+\hat{\beta}_{1} *$ COST, evaluating (24) setting $\Psi$ equal to $\hat{A}_{\operatorname{COST}} * \hat{\Sigma} * \hat{A}_{\operatorname{COST}}$, and subtracting portion of the resulting volatility due to the shock variances. The remaining rows present the fraction of volatility due to demand linkages, symmetric local spillovers, asymmetric local spillovers, and interactions among COST, DEM and SIZE. Variance decompositions are reported for each city; the final column reports averages over the sample cities.

The results of Table 5 suggest that both aggregate shocks and local spillovers are important sources of city-level employment volatility. Aggregate shocks account for between 23 and 69 percent of local employment volatility, with an average share of 42.8 percent. Local spillovers explain 32.1 percent of city employment volatility on average, with symmetric spillovers contributing somewhat more to volatility than asymmetric spillovers. Input-output linkages have barely any significance to local volatility. Local common shocks are not important to local volatility on average, although they do appear to 
be somewhat important for Los Angeles and Boston.

I should point out that these variance decompositions may either understate or overstate the role of aggregate shocks relative to local spillovers in generating local volatility. On the one hand, there may be important aggregate shocks other than oil prices and monetary policy; omitting these shocks would tend to minimize the importance of aggregate factors. On the other hand, recall that I estimate the impact of aggregate shocks by regressing employment growth on a constant, oil price growth, and monetary policy city-industry by city-industry; local spillovers are assumed to affect only the residuals from these regressions. This procedure is likely to overstate the role of aggregate shocks, for two reasons. First, there are only ten observations on employment growth for each city-industry; with so few degrees of freedom, the projection of the data on the aggregate shocks is likely to produce a high sample R-squared even for city-industries that are unaffected by aggregate shocks in the population.

Second, my procedure assigns all comovement due to the matrix G to common shocks, implicitly assuming that local spillovers and other complementarities play no role in transmitting aggregate shocks across local sectors. This assumption is unlikely to be true. For instance, suppose monetary policy has a direct impact only on durable goods industries. If there are symmetric local spillovers, then a monetary shock that reduces activity in durable industries in a particular city will also reduce activity in local nondurable industries. My econometric procedure would assign the decline in both sectors to aggregate shocks, thus failing to distinguish direct effects from indirect effects resulting from local spillovers. In Shea (1995), I decompose the estimated impact of aggregate shocks into direct effects 
and indirect effects working through complementarities. While I do not attempt such a decomposition here, I would point out that in Shea (1995), I find that less than 10 percent of the total impact of aggregate shocks is due to direct effects.

\section{TRANSPORT COSTS AND NONTRADED GOODS}

The previous results suggest that symmetric and asymmetric local activity spillovers are significant sources of local comovement and volatility. But exactly what form do these local spillovers take? Why exactly does the activity of one city-industry depend on the activity of other local industries? In this section, I explore the possibility that local spillovers are due to high transport costs that limit the intercity tradeability of certain goods.

Transport costs and nontradeability could affect the pattern of local comovement in two ways. First, input-output linkages are likely to bind more strongly at the local level if the upstream input is nontradeable. Consider, for instance, the link between the Chicago tire industry and the Chicago automobile industry. If tires are easy to transport across cities, then an adverse supply shock to the Chicago tire industry need not have a large impact on the Chicago auto industry, since Chicago autos can easily substitute into tires from other cities. Similarly, an adverse demand shock to Chicago autos need not have a large impact on Chicago tires, since Chicago tires can be sold to auto manufacturers in other cities. On the other hand, if tires are costly to transport, then Chicago autos will buy mostly local tires, while Chicago tires will be sold mostly to local autos; thus, shocks to Chicago tires will have a large effect on Chicago autos, and vice-versa. Given the pattern of factor demand linkages measured at the national 
level, comovement between a pair of local industries should therefore increase as the upstream input becomes less tradeable. Moreover, tradeability should also affect industry location in the long run. As tires become less tradeable, the auto and tire industries should locate in the same cities in order to minimize transport costs. Controlling for national input-output linkages, then, transport costs should cause the pattern of comovement within a particular city to be related to the pattern of industry clustering in other cities, since the latter contains information about tradeability not included in the input-output data. Transport costs and nontradeability thus can potentially explain the evidence for asymmetric local spillovers reported above.

Second, nontraded consumer goods are likely to respond strongly to the overall level of local tradeables activity in the presence of aggregate demand spillovers. Suppose that the Detroit auto industry experiences an increase in sales, increasing the take-home pay of its workers. To the extent that autos are tradeable, so that the increase in auto sales comes mostly from other cities, then the increase in local income should exceed the increase in local car spending, and on net the favorable shock to autos should increase Detroit's aggregate demand for other consumer goods. For tradeable consumer goods, the impact of this increase in aggregate demand will be dispersed over many cities; for nontraded consumer goods, however, the shock will be concentrated locally. Furthermore, shocks to the auto industry will have a larger effect on Detroit's demand for nontraded consumer goods than shocks to the clothing industry, since autos are more important to Detroit's economy than clothing. Transport costs and nontradeability can thus potentially explain the evidence for symmetric local activity spillovers reported above. Notice, however, that if local activity spillovers 
take the form of aggregate external economies of scale (as in the model presented above), rather than aggregate demand linkages, then there is no obvious reason to expect a relationship between an industry's tradeability and its' responsiveness to local activity.

To investigate the importance of transport costs and nontraded goods for local comovement, I use data from Table 3 of the 1977 Census of Transportation's Commodity Transportation Survey Summary, which provides tons shipped broken down by length of shipment for disaggregated manufacturing industries. This table groups industries according to the Transportation Commodity Classification (TCC), rather than the Standard Industrial Classification (SIC). Fortunately, the two classifications are comparable for most of my sample industries; details on the conversion from the TCC to the SIC are presented in the appendix. I measure industry i's nontradeability as LOCAL $_{i}$, equal to industry tons shipped fewer than 100 miles divided by total industry tons shipped. ${ }^{10}$ LOCAL measures the fraction of an industry's demand that comes from local sources; a high value of LOCAL suggests high transport costs and low tradeability. The appendix lists LOCAL for all industries. Industries for which local demand is paramount include newspapers (92.6 percent of demand generated locally) and concrete ( 89.7 percent); industries for which local demand is unimportant include communication equipment ( 17.4 percent) and measuring instruments ( 8.8 percent).

I allow transport costs to affect comovement in cities by respecifying my model of local fluctuations as follows:

$$
\begin{aligned}
y_{t}=\mu+G * a_{t}+A * \varepsilon_{t}+v_{t} \\
A= \\
+ \text { ID }+\beta_{1} * \operatorname{COST}+\beta_{2} * \text { DEM }+\beta_{3} * \text { SIZE } \\
+\beta_{5} * \text { COSTLO }+\beta_{6} * \text { DEMLO }+\beta_{7} * \text { SIZELO }
\end{aligned}
$$




$$
\begin{aligned}
\Omega=\beta_{4} & \text { CITY }+\alpha * \text { COMMON } \\
& +\beta_{8} * \text { CITYLO }+\beta_{9} * \text { LOCAL }
\end{aligned}
$$

where COSTLO, DEMLO, SIZELO, CITYLO, and LOCAL are $\mathrm{N}$-by-N matrices with zero diagonals, and where all other matrices and vectors are the same as in the baseline specification.

The specification (32)-(34) allows an industry's tradeability to affect its comovement with other local industries, both on its own and in interaction with other sources of local comovement. COSTLO and DEMLO allow for interaction between tradeability and input-output linkages. The $[i, k]$ element of COSTLO equals $\operatorname{LOCAL}_{k} * \operatorname{COST}[i, k]$, while the $[i, k]$ element of DEMLO equals $\operatorname{LOCAL}_{\mathbf{i}} * \operatorname{DEM}[\mathbf{i}, \mathbf{k}]$. Recall that $\operatorname{COST}[\mathbf{i}, \mathbf{k}]$ measures how strongly shocks propagate from upstream supplier $k$ to downstream user $i$, while DEM[i,k] measures how strongly shocks propagate from downstream user $k$ to upstream supplier $i$. The specification of COSTLO and DEMLO thus allows the strength of local input-output linkages to depend on upstream input tradeability; the discussion above suggests that $\beta_{5}$ and $\beta_{6}$ are likely to be positive.

SIZELO, meanwhile, allows nontraded consumer goods industries to respond strongly to local tradeables activity. The $[i, k]$ element of SIZELO equals FINAL FI $^{*} \operatorname{LOCAL}_{i} *\left(1-\operatorname{LOCAL}_{k}\right) * \operatorname{SIZE}[\mathbf{i}, k]$, where FINAL $_{i}$ is the fraction of industry i's output devoted to consumption; FINAL is measured using 1977 national input-output data. If $\beta_{7}$ is positive, this specification implies that the strength of aggregate demand spillovers from local industry $k$ to local industry i increases with four factors: (1) industry k's size; (2) the extent to which $k$ is tradeable, so that an increase in $k^{\prime} s$ sales on net raises local demand for other consumer goods; (3) the extent to which i is a consumer good; and (4) the extent to which I's demand is generated locally. 11 
Finally, the $[i, k]$ element of LOCAL equals $\operatorname{LOCAL}_{i} * \operatorname{LOCAL}_{k}$, while the $[i, k]$ element of CITYLO equals LOCAL $[i, k] * \operatorname{CITY}[i, k]$. LOCAL thus allows tradeability to influence local comovement in a generic way, without any interaction with other local linkages, while CITYLO allows the impact of tradeability to depend on the extent to which $i$ and $k$ cluster together in space. The discussion above did not suggest any obvious reason to expect $\beta_{8}$ or $\beta_{9}$ to be positive; I include LOCAL and CITYLO simply to capture any interactions between transport costs, spatial clustering and local comovement that do not fit into either of the two transport cost storles outlined above.

Table 6 presents results from estimating equations (32)-(34). If transport costs and locally traded goods were responsible for local spillovers, we would expect to find positive and significant coefficients on COSTLO, DEMLO and SIZELO, as well as perhaps LOCAL and CITYLO. We would also expect that controlling for transport costs and tradeability would drive the coefficients on SIZE and CITY towards zero, perhaps rendering them insignificant.

Viewed in the light of these criteria, the results in Table 6 are disappointing. The coefficient on SIZELO is negative and significant, implying that the level of local activity has stronger impacts on traded than on nontraded local goods; this is the opposite of what one would expect under local demand spillovers. Furthermore, the coefficients on COSTLO and DEMLO are insignificant and of the wrong sign, suggesting that nontraded inputs do not have especially strong links with local downstream users. The coefficient on LOCAL is negative and significant, while the coefficient on CITYLO is positive and significant, implying that the relationship between clustering and comovement is stronger for pairs of nontraded industries than for traded industries. While this 
last result is intriguing, it is also puzzling, since the transport cost stories outlined above did not suggest any additional interactions between spatial clustering, comovement and tradeability beyond those captured by COSTLO, DEMLO and SIZELO. Including the nontradeability variables does not eliminate the evidence for generic local spillovers found in the baseline specification; while the coefficient on CITY is closer to zero and less significant than in the baseline specification, the coefficient on SIZE is larger and more significant. Furthermore, variance decompositions similar to those reported in Table 5 (available from the author) show that the nontradeability variables collectively account for a negative share of local employment variance, suggesting that transport costs act to reduce rather than increase local volatility. All in all, local spillovers do not appear to arise because of transport costs and nontraded goods.

\section{CONCLUSION}

This paper has examined the pattern of short-run comovement among 387 manufacturing industries located in seven large US cities. I have found that both symmetric and asymmetric spillovers are significant sources of local comovement, and that local spillovers are responsible for roughly one-third of local manufacturing employment volatility. I have attempted to put some structure on the elusive concept of "local synergy" by investigating the role of transport costs and limited intercity tradeability of certain goods in generating local comovement. But this attempt has had little success; local spillovers apparently take the form of some other, unidentified local synergy.

Future work should explore alternative explanations for the local spillovers found in this paper. For instance, the findings of this 
paper might be due to the interindustry pattern of conglomeration. A parent company with subsidiaries in several industries might prefer to keep its operations geographically concentrated to save on administrative costs. Moreover, establishments belonging to the same parent company might comove more strongly than similar but unconglomerated establishments, if there are company-specific shocks or if establishment-level shocks propagate within companies due to cash-flow constraints on investment. Thus, industries that are linked by conglomeration might move together in both space and in time, even after controlling for input-output linkages. Alternative explanations such as these should be easy to incorporate into the empirical framework used in this paper, provided the implied interindustry linkages can be expressed as functions of observable variables. 


\section{APPENDIX}

\section{Maximum Likelihood Estimation}

Suppose first that we have data for Chicago only. The log likelihood function for 10 observations on the vector $\tilde{y}$ is given by

$$
\log L=-(10 * 125) / 2-(10 / 2) * \log |\Psi|-(1 / 2) \sum_{t=1}^{10}\left(\tilde{y}_{t}^{\prime}, \tilde{\Psi}^{-1} \tilde{y}_{t}\right)
$$

where $\tilde{\Psi}=A * \Sigma * A^{\prime}+\Omega$. From Greene (1990, p. 517-18), one can rewrite the log likelihood function as

$$
\log L=-(10 * 126) / 2-(10 / 2) * \log |\tilde{\Psi}|-(10 / 2) * \operatorname{tr}\left(\tilde{\Psi}^{-1} S\right)
$$

where $\operatorname{tr}$ denotes trace, and where

$$
S=(1 / 10) \sum_{t=1}^{10} \tilde{y}_{t}^{*} \tilde{y}_{t}^{\prime}
$$

is the moment matrix of the data. From Greene (1990, p. 518), one can show that

$$
\partial(\log \mathrm{L}) / \mathrm{d} \tilde{\Psi} \equiv \mathrm{B}=-(10 / 2) *\left[\tilde{\Psi}^{-1}-\tilde{\Psi}^{-1} * \mathrm{~S} * \tilde{\Psi}^{-1}\right]
$$

Furthermore, one can show that in the baseline specification

$$
\partial \tilde{\Psi} / \mathrm{d} \beta_{1} \equiv C_{1}=A * \Sigma * \operatorname{CosT}+\operatorname{cosT} * \Sigma * A^{\prime}
$$

It thus follows that

$$
\partial(\log L) / d \beta_{1}=\operatorname{tr}\left(B * C_{1}^{\prime}\right)
$$

in other words, the effect of $\beta_{1}$ on the log likelihood is equal to the effect of $\beta_{1}$ on the [1,1] element of $\tilde{\Psi}$ times the effect of the $[1,1]$ 
element of $\tilde{\Psi}$ on $\log (L)$, plus the effect of $\beta_{1}$ on the [1,2] element of $\tilde{\Psi}$ times the effect of the [1,2] element of $\tilde{\Psi}$ on $\log (L)$, and so on. One can similarly compute the gradient of $\log (\mathrm{L})$ with respect to any other parameter premultiplying an element of the matrix A.

Next, for the variance matrix $\Sigma$, one can show that

$$
\partial \tilde{\Psi} / \mathrm{d} \Sigma_{i k} \equiv D_{i}=A[,, i] * A[, i]^{\prime}
$$

where $A[,, i]$ is the $i$ th column of $A$. It follows that the gradient of the $\log$ likelihood with respect to the element [i,i] of the diagonal matrix $\Sigma$ is given by

$$
\partial(\log L) / d \Sigma_{i i}=\operatorname{tr}\left(B * D_{i}^{\prime}\right)
$$

Finally, the gradient of the log likelihood with respect to $\beta_{4}$ (or, analagously, with respect to any parameter premultiplying a matrix of $\Omega$ ) can easily be seen to equal

$$
\partial(\log L) / d \beta_{4}=\operatorname{tr}\left(B * C I T Y^{\prime}\right)
$$

Now suppose we have data for seven cities. I assume that the parameters $\beta$ are the same over all cities, while $\alpha$ and the elements of $\Sigma$ are different across cities. The matrices COST, DEM and so on are city-specific, as described below. I estimate these parameters by maximizing

$$
V=\sum_{j=1}^{7} \log L_{j},
$$

where $\log \mathrm{L}_{j}$ is the $\log$ likelihood for city $j$, defined as above.

The gradient of $V$ with respect to $\beta_{1}$ is 


$$
\partial V / \partial \beta_{1}=\sum_{j=1}^{7} \partial\left(\log L_{j}\right) / \partial \beta_{1},
$$

where the terms inside the summation are as above, with $B$ and $C_{1}$ varying across cities. A similar holds for the gradient of $V$ with respect to any of the $\beta$ parameters. Since the $\alpha^{\prime} s$ and the of $\Sigma$ vary across cities, the gradient of $V$ with respect to an $\alpha$ or an element of $\Sigma$ for a given city $j$ is exactly as before, without any need to sum over cities.

\section{Data Matrices}

I construct COST and DEM for each city using data from the 1977 detailed US input-output study. To begin with, I construct a 125-by-125 matrix COSTUS as follows. First, I construct a 157-by-157 matrix $\beta$, whose [k,i] element equals the share of industry i's cost directly attributable to industry k. I construct $\beta$ from raw input-output data using methods described in Shea (1991 and 1993); in the terminology introduced in these papers, $\beta[k, i]$ is the Direct Cost Share of $k$ in $i$. As in this previous work, $\beta[k, i]$ includes both i's purchases of $k$ as a material input and an imputed service flow from i's use of $k$ as capital. The 157 industries consist of the 125 manufacturing industries listed below plus 32 nonmanufacturing industries 1 isted in the appendix to Shea (1995). Next, I construct a 157-by-157 "total requirements" matrix TOTAL as follows:

$$
\text { TOTAL }=\left([I-\beta]^{-1}\right)^{\prime} \text {. }
$$

where I is a 157-by-157 identity matrix. I construct COSTUS by taking the rows and columns of TOTAL corresponding to the 125 sample manufacturing industries. For a particular city $\mathbf{j}$, then, the matrix COST equals the rows and columns of COSTUS corresponding to the industries for 
which data is available for city $j$; for Los Angeles, for instance, COST is a 102-by-102 matrix, while for Philadelphia COST is a 30-by-30 matrix. Given COST for city $j$, I construct DEM for city $j$ as follows:

$$
\operatorname{DEM}[i, k]=\left(\operatorname{COST}[k, i] * a_{k}\right) / \sum_{i=1}^{N}\left(\operatorname{CosT}[z, i] * a_{z}\right),
$$

where $N$ is the number of sample industries for city $j$, and where $a_{k}$ is industry k's final demand in 1977, defined as the sum of direct purchases from consumption, government, the 32 nonmanufacturing industries, and any manufacturing industries not included in the sample for city $j$ due to data unavailability.

The matrix CITY for city $j$ is constructed by forming the 125-by-125 matrix CITYUS following equation (29) in the text, and then taking the rows and columns of CITYUS corresponding to the industries for which data is available for city $j$.

The matrices SIZE, COSTLO, DEMLO, SIZELO, LOCAL, and CITYLO are constructed as described in the text.

Converting from the TCC to the SIC

I estimate industry tradeability using data from Table 3 of the 1977 Census of Transportation Commodity Transportation Survey Summary, which uses the Transport Commodity Classification (TCC) rather than the Standard Industrial Classification (SIC). In converting from the TCC to the SIC, I assume that data for a particular TCC industry applies to the identically-numbered SIC industry, with the following exceptions:

TCC industries 2031 and 2036 ( $\mathrm{f}$ ish products) are assigned to SIC 209. 
TCC industries 206 and 207 (sugar and confectionary products) are assigned to SIC 206.

TCC industries 2091, 2092, 2093, 2094 and 2096 (oils and shortening) are assigned to SIC 207.

TCC industry 24992 (skids, pallets and platforms) is assigned to SIC 244.

TCC industries 2433 and 37911 (wood buildings and mobile homes) are assigned to SIC 245.

TCC industry 251 (wood and metal furniture) is assumed to apply to both SIC 251 and SIC 252.

TCC industries 311 and 312 are assigned to SIC 311.

TCC industry 316 (luggage, handbags and personal goods) is assumed to apply to both SIC 316 and SIC 317 .

TCC industries 33911 and 33921 (metal forgings) are assigned SIC 346.

TCC industry 3491 (metal containers) is assigned to SIC 341.

TCC industries 348 and 349 (wire and miscellaneous metal products) are assigned to SIC 349.

TCC industry 3611 (electric measuring instruments) is assigned to SIC 382.

There are no TCC industries comparable to SIC industries 275,334 , 347 or 348. Table 9 of the Commodity Transportation Survey Summary, however, does include tons and ton-miles shipped for all three-digit SIC industries, so that I can compute mean distance shipped (ton-miles divided by tons) for any three-digit industry. I therefore set LOCAL for SIC 275 equal to LOCAL for SIC 274 divided by 1.28 , which is the ratio of mean distance shipped for SIC 275 to mean distance shipped for SIC 274 (I thus assume that a high value of mean distance shipped corresponds to higher 
tradeability and thus a lower value for LOCAL). Analagously, I set LOCAL for SIC 334 equal to LOCAL for SIC 333 divided by 0.46 ; I set LOCAL for SIC 347 equal to LOCAL for SIC 346 divided by 0.51 , and LOCAL for SIC 348 equal to LOCAL for SIC 346 divided by 1.13 .

Sample Manufacturing Industries

The table below lists the 125 potential sample manufacturing industries for each city, and indicates (with an asterik) which industries have data available for each city. Cities are abbreviated as follows: New York is NY; Los Angeles is LA; Chicago is $\mathrm{CH}$; Philadelphia is PH; Detroit is DE; San Francisco is SF; and Boston is BN. The final column, LOCAL, shows the share of each industry's total tons shipped that is shipped less than $100 \mathrm{miles}$.

SIC 201: Meat Products

SIC 202: Dairy Products

SIC 203: Canned Fruits \& Vegetables

SIC 204: Grain Mill Products

SIC 205: Bakery Products

SIC 206: Sugar \& Confectionary

SIC 207: Fats and Oils

SIC 208: Beverages

SIC 209: Miscellaneous Food

SIC 21: Tobacco Manufactures

SIC 221-3 \& 226: Broadwoven Fabrics

SIC 224: Narrow Fabrics

SIC 225: Knitting Mills

SIC 227: Floor Covering Mills

SIC 228: Yarn and Thread Mills

SIC 229: Miscellaneous Textiles

SIC 23: Clothing

SIC 241: Logging Camps \& Contractors

SIC 242: Sawmills \& Planing Mills

SIC 243: Millwork and Plywood

SIC 244: Wood Containers

SIC 245: Wood Buildings \& Mobile Homes

SIC 249: Miscellaneous Wood Products

SIC 251: Household Furniture

SIC 252: Office Furniture

SIC 253: Public Building Furniture

SIC 254: Office Fixtures

SIC 259: Miscellaneous Furniture

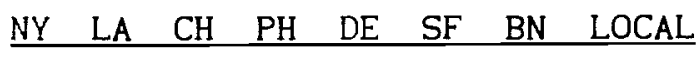

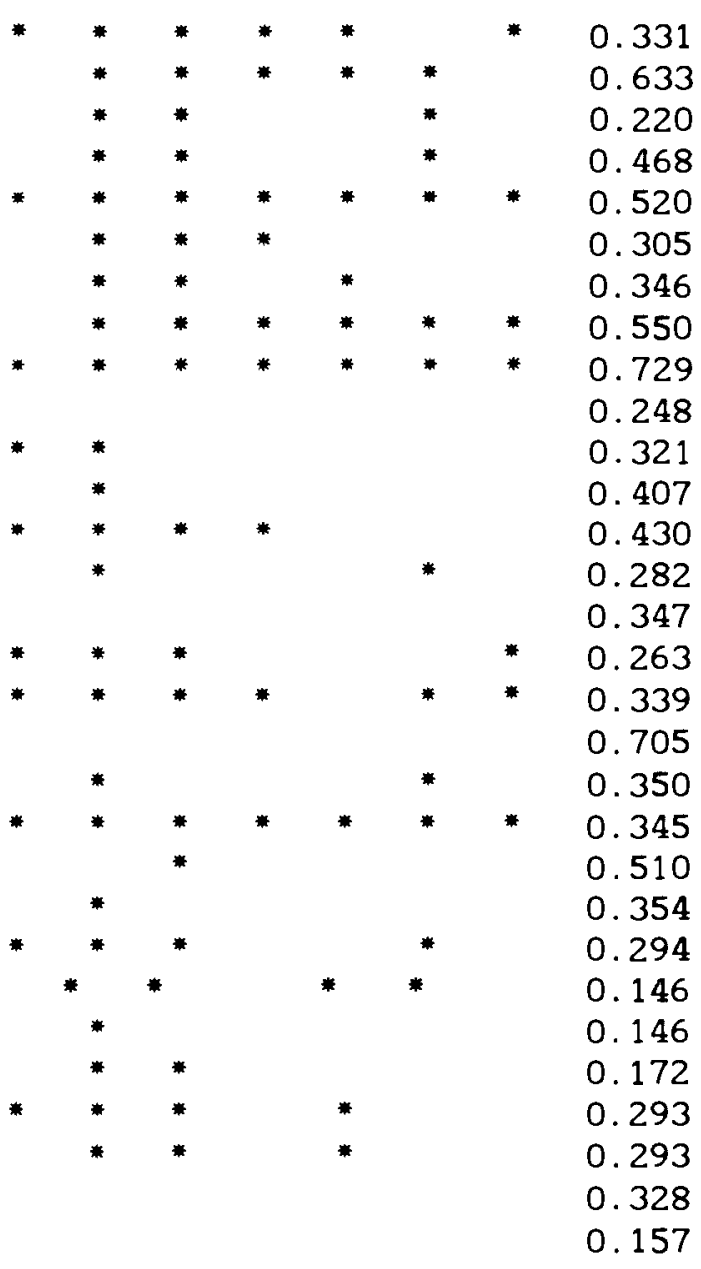

SIC 261: Pulp Mills

SIC 262: Paper Mills

0.157 
SIC 263: Paperboard Mills

SIC 264: Converted Paper Products

SIC 265: Paperboard Containers

SIC 266: Building Paper \& Board

SIC 271: Newspapers

SIC 272: Periodicals

SIC 273: Books

SIC 274: Miscellaneous Publishing

SIC 275: Commercial Printing

SIC 276: Manifold Business Forms

SIC 277: Greeting Card Publishing

SIC 278: Blankbooks \& Bookbinding

SIC 279: Printing Trade Services

SIC 281 \& 286: Industrial Chemicals

SIC 282: Synthetic Materials

SIC 283: Drugs

SIC 284: Soaps \& Toiletries

SIC 285: Paints

SIC 287: Agricultural Chemicals

SIC 289: Miscellaneous Chemicals

SIC 291: Petroleum Refining

SIC 295: Paving \& Roofing Materials

SIC 299

SIC 301:

SIC 302:

SIC 303:

SIC 304:

SIC 306:

SIC 307:

SIC 311:

SIC 313:

SIC 314:

SIC 315:

SIC 316:

SIC 317:

SIC 319:

SIC 321-3:

SIC 324:

SIC 325:

SIC 326:

SIC 327:

SIC 328:

SIC 329:

SIC 331:

SIC 332:

SIC 333:

SIC 334:

SIC 335:

SIC 336:

SIC 339:

SIC 341:
Miscellaneous Petroleum

Tires \& Inner Tubes

Rubber \& Plastics Footwear

Reclaimed Rubber

Rubber \& Plastic Hose

Miscellaneous Rubber

Miscellaneous Plastics

Leather Tanning \& Finishing

Boot \& Shoe Cut Stock

Leather Gloves \& Mittens

Luggage

Personal Leather Goods

Miscellaneous Leather Goods

Glass Products

Cement, Hydraulic

Structural Clay Products

Pottery \& Related Products

Concrete, Gypsum \& Plaster

Cut Stone \& Stone Products

Misc. Nonmetallic Minerals

Blast Furnaces \& Steel Mills

Iron and Steel Foundries

Primary Nonferrous Metals

Secondary Nonferrous Metals

Nonferrous Metal Mills

Nonferrous Foundries

Misc. Primary Metal Products

Metal Cans \& Containers
Footwear, Except Rubber

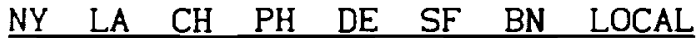

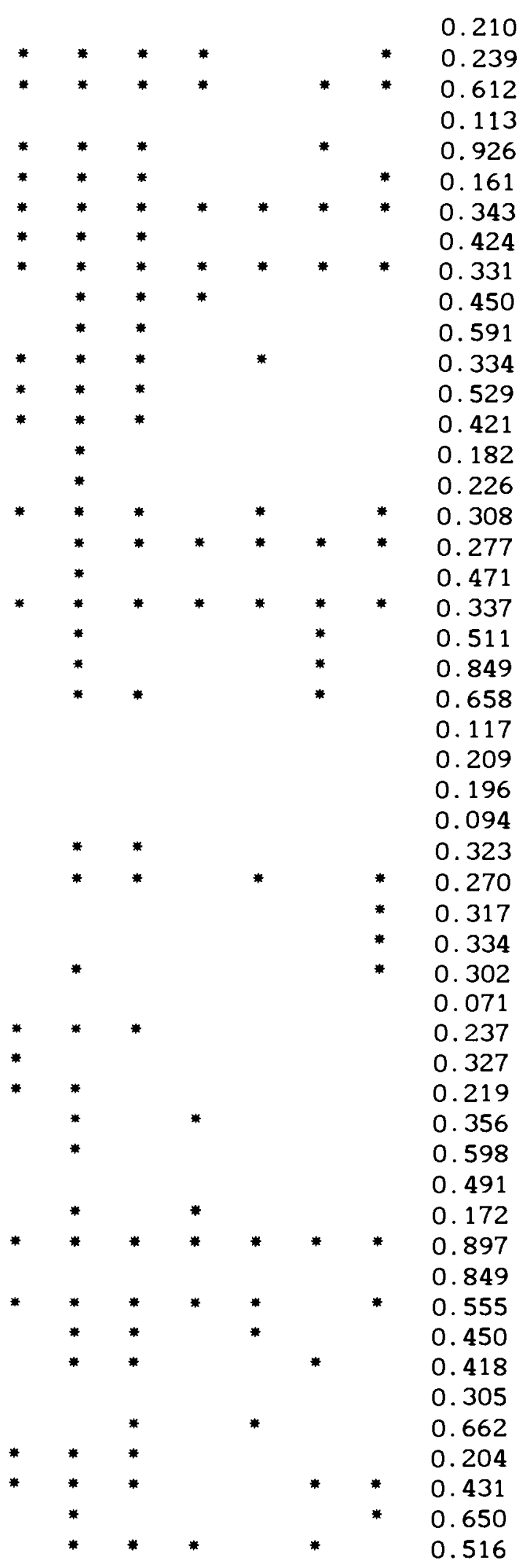


SIC 342: Cutlery, Tools \& Hardware

SIC 343: Plumbing \& Heating Equipment

SIC 344: Fabricated Structural Metal

SIC 345: Screw Machine Products

SIC 346: Metal Forgings \& Stampings

SIC 347: Coating \& Engraving Services

SIC 348: Ordnance \& Accessories

SIC 349: Misc. Fabricated Metal

SIC 351: Engines and Turbines

SIC 352: Farm \& Garden Machinery

SIC 353: Construction Machinery

SIC 354: Metalworking Machinery

SIC 355: Special Industry Machinery

SIC 356: General Industrial Machinery

SIC 357: Office \& Computing Machines

SIC 358: Service Industry Machinery

SIC 359: Misc. Nonelectric Machinery

SIC 361: Electric Distribution

SIC 362: Electric Industrial Apparatus

SIC 363: Household Appliances

SIC 364: Electric Lighting \& Wiring

SIC 365: Radio \& TV Equipment

SIC 366: Communication Equipment

SIC 367: Electronic Components

SIC 369: Misc. Electrical Machinery

SIC 371: Motor Vehicles

SIC 372 \& 376: Aerospace Equipment

SIC 373: Ships and Boats

SIC 374: Railroad Equipment

SIC 375: Motorcycles, Bicycles \& Parts

SIC 379: Misc. Transport Equipment

SIC 381: Scientific Instruments

SIC 382: Measuring Instruments

SIC 383: Optical Instruments

SIC 384: Medical Instruments

SIC 385: Opthalmic Goods

SIC 386: Photographic Equipment

SIC 387: Watches \& Clocks

SIC 391: Jewelry \& Silverware

SIC 393: Musical Instruments

SIC 394: Toys \& Sporting Goods

SIC 395: Office Supplies

SIC 396: Clothing Accessories

SIC 399: Other Misc. Manufacturing $\begin{array}{llllllll}\text { NY } & \text { LA } & \mathrm{CH} & \mathrm{PH} & \mathrm{DE} & \mathrm{SF} & \mathrm{BN} & \mathrm{LOCAL}\end{array}$

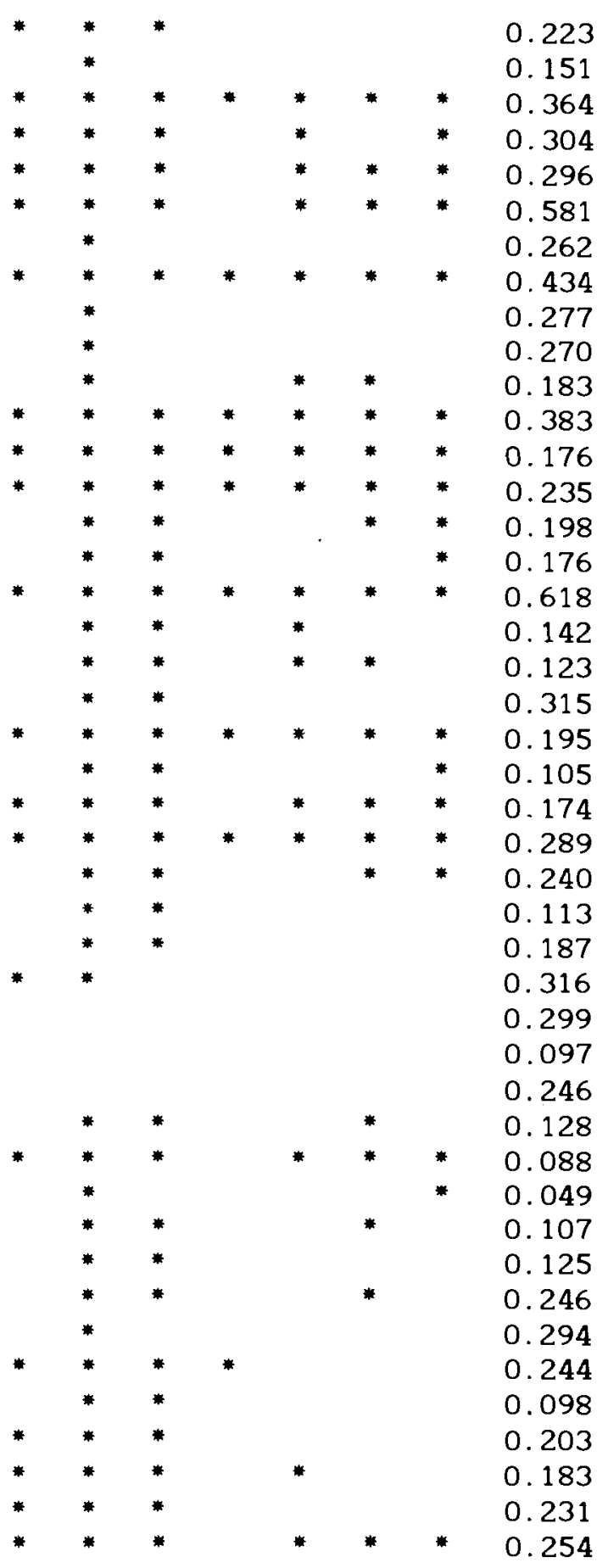


Baxter, M., and King, R.

(1991) Productive Externalities and Business Cycles. Federal
Reserve Bank of Minneapolis Institute for Empirical
Macroeconomics Discussion Paper 53.

Blanchard, O., and Katz, L.

(1992) Regional Evolutions. Brookings Papers on Economic Activity, 1:1992: 1-61.

Ciccone, A., and Hall, R.

(1993) Productivity and the Density of Economic Activity. Hoover Institution Working Paper.

Cooper, R., and Haltiwanger, J.

(1990) Inventories and the Propagation of Sectoral Shocks. American Economic Review, 80: 170-190.

Diamond, $P$.

(1982) Aggregate Demand Management in Search Equilibrium. Journal of Political Economy, 90: 881-894.

Gardocki, B., and Baj, J.

(1985) Methodology for Estimating Nondisclosure in County Business Patterns. Northern Illinois University mimeo. 
Glaeser, E., Kallal, H., Scheinkman, J., and Shleifer, A.

(1992) Growth in Cities. Journal of Political Economy, 100: $1126-1152$.

Greene, W.

(1990) Econometric Analysis. New York: Macmillan Publishing.

Head, K., Ries, J., and Swenson, D.

(1994) Agglomeration Benefits and Location Choice: Evidence from Japanese Manufacturing Investment in the United States. National Bureau of Economic Research Working Paper 4767.

Henderson, $V$.

(1994) Externalities and Industrial Development. National Bureau of Economic Research Working Papper 4730.

Krugman, P.

(1991) Geography and Trade. Cambridge: MIT Press.

Lettau, $M$.

(1994) Wage Adjustment in Local Labor Markets: Do the Wage Rates in All Industries Adjust? Bureau of Labor Statistics Working Paper 253. 
Long, J. and Plosser, C.

(1983) Real Business Cycles. Journal of Political Economy, 91: 39-69.

Long, J. and Plosser, C.

(1987) Sectoral Versus Aggregate Shocks. American Economic Review, 77: 333-336.

Marsha11, A.

(1949) Principles of Economics, eighth edition. New York: The Macmillan Company.

Miracky, W.

(1992) Technological Spillovers, the Product Cycle and Regional Growth. Massachusettes Institute of Technology mimeo.

Murphy, K., Shleifer, A., and Vishny, R.

(1989) Building Blocks of Market Clearing Business Cycle Models. NBER Macroeconomics Annual, eds. O. Blanchard and $\mathrm{S}$. Fischer. Cambridge: MIT Press.

Neumann, G., and Topel, R.

(1991) Employment Risk, Diversification, and Unemployment. Quarterly Journal of Economics, 105: 1341-1365. 
Rauch, J.

(1993) Productivity Gains from Geographic Concentration of Human Capital: Evidence from the Cities. Journal of Urban Economics, 34: 380-400.

Shea, J.

(1991) The Input-Output Approach to Instrument Selection: Technical Appendix. University of Wisconsin Social Systems Research Institute Working Paper 9115.

(1993) The Input-Output Approach to Instrument Selection. Journal of Business and Economic Statistics, 11: 145-155.

(1995) Complementarities and Comovements. University of Wisconsin mimeo.

Startz, R.

(1989) Monopolistic Competition as a Foundation for Keynesian Macroeconomic Models. Quarterly Journal of Economics. 104: 737-752.

Topel, R.

(1986) Local Labor Markets. Journal of Political Economy, 94: S111-S143. 


\title{
FOOTNOTES
}

\begin{abstract}
${ }^{1}$ Note that, because I have only ten years of data, the estimated 125-by-125 matrix CORREMP will not be of full rank. This implies that, in the sample, the estimated elements of CORREMP will be correlated among themselves, implying that OLS standard errors will not be correct in equation (4); unfortunately, there is no obvious way of correcting the standard errors in this case. The results in equation (4) thus should not be taken too seriously; they are meant only to illustrate the relationship between temporal and spatial correlation in a simple fashion.
\end{abstract}

${ }^{2}$ Neumann and Topel (1991) find that cities with a poorly diversified industrial base do indeed have higher unemployment rates on average than cities with a well-diversified industrial base.

${ }^{3}$ The data were provided to me by Bill Miracky, who in turn obtained the data from the Center for Governmental Studies at Northern Illinois University.

${ }^{4}$ The Miracky-Northern Illinois data impute nondisclosures using the algorithm proposed by Gardocki and Baj (1985), who combine information on the number of county-industry establishments in each size range with state-level information on the average number of employees per establishment for each range in each industry. I use this imputed data to compute the series EMP2 described in the text, as well as the measure CITCORR described in the introduction and the matrix CITYCOV 
described later in the text.

5 For a given city, this fraction is defined as the eleven-year average of EMP2 summed over industries included in the sample, divided by the eleven-year average of EMP2 summed over all 125 manufacturing industries.

${ }^{6}$ In terms of previous terminology, aggregate employment for a particular city at time $t$ is defined as the sum of EMP1 over all sample industries for that city at time $t$. Meanwhile, the ith element of SHARE for a particular city equals the eleven-year average of EMP2 for industry $i$ in that city, divided by the eleven-year average of EMP2 summed over all sample industries for that cities. For each city, the elements of SHARE thus sum to one.

${ }^{7}$ In terms of previous terminology, $\operatorname{SIZE}[i, k]$ for Chicago is def ined as the eleven-year average of EMP2 for industry $k$ in Chicago, divided by the eleven-year average of EMP2 summed over all 125 potential sample manufacturing industries in Chicago. Notice that rows of SIZE do not sum to one; they sum instead to the third column ("Coverage") in Table 1.

\footnotetext{
${ }^{8}$ In terms of previous terminology, SHARE $j i$ is defined as the eleven-year average of EMP2 for industry $i$ in city $j$, divided by the eleven-year average of EMP2 for industry $i$ summed over the 93 cities not included in the sample.
} 
${ }^{9}$ In Shea (1995), I estimate a model using national employment for disaggregated manufacturing industries over the period 1958-1986, controlling for the effects of oil prices and monetary policy as in this paper. I estimate a coefficient on COST of 0.325 , and a coefficient on DEM of 0.857 ; both estimates are statistically significant.

${ }^{10}$ Experiments defining LOCAL as the fraction of industry tons shipped less than 200 miles yielded qualitatively similar results.

${ }^{11}$ Experiments defining SIZELO $[i, k]$ excluding the terms FINAL and/or (1 - LOCAL $_{k}$ ) yielded qualitatively similar results. 
TABLE 1

Sample Composition

\begin{tabular}{lcccccc} 
& & & & & ---Employment Volatility--- \\
City & Sectors & Coverage & $\begin{array}{c}\text { Average } \\
\text { Corr }\end{array}$ & Actual & $\begin{array}{c}\text { Implied } \\
\text { Due To } \\
\text { Comovement }\end{array}$ \\
\hline New York & 50 & 0.717 & 0.224 & $3.32 \%$ & $3.32 \%$ & 86.6 \\
Los Angeles & 102 & 0.983 & 0.150 & $4.53 \%$ & $4.66 \%$ & 88.4 \\
Chicago & 79 & 0.901 & 0.107 & $4.30 \%$ & $4.22 \%$ & 88.3 \\
Philadelphia & 30 & 0.425 & 0.079 & $3.70 \%$ & $3.81 \%$ & 72.6 \\
Detroit & 39 & 0.463 & 0.168 & $7.86 \%$ & $7.87 \%$ & 80.8 \\
San Francisco & 45 & 0.752 & 0.155 & $6.94 \%$ & $7.11 \%$ & 74.9 \\
Boston & 42 & 0.716 & 0.172 & $5.57 \%$ & $5.82 \%$ & 75.1
\end{tabular}

NOTES: This table presents descriptive statistics for the sample. The second column reports the number of sample industries for each city, while the third column shows the fraction of city manufacturing employment accounted for by the sample industries. The third column reports the average within-city pairwise correlation among sample city-industries. The fourth column shows the actual standard deviation of annual employment growth for the city-level aggregate defined by summing employment over sample industries, while the fifth column reports the standard deviation implied by equation (24) in the text, using the observed covariance matrix of city-industry employment growth. The final column shows the fraction of the city-level variance implied by equation (24) that can be attributed to comovement among city-industries. See the text for additional information. 
TABLE 2

Baseline Specification

$$
\begin{aligned}
& y_{t}=\mu+G * a_{t}+A * \varepsilon_{t}+v_{t} \\
& A=I D+\beta_{1} * \operatorname{COST}+\beta_{2} * \mathrm{DEM}+\beta_{3} * \text { SIZE } \\
& \operatorname{Var}\left(v_{t}\right)=\Omega=\beta_{4} * \operatorname{CITY}+\alpha * \text { COMMON } \\
& \begin{array}{llll}
\beta_{1} & \beta_{2} & \beta_{3} & \beta_{4} \\
\hline
\end{array} \\
& \begin{array}{llll}
0.200 & 0.349 & 0.892 & 1.671
\end{array} \\
& * *(0.100) * *(0.142) \quad * *(0.246) \quad * *(0.321)
\end{aligned}
$$

\begin{tabular}{ccccccc}
${ }^{\alpha}$ & $\alpha_{\mathrm{NA}}$ & $\alpha_{\mathrm{CH}}$ & $\alpha_{\mathrm{PH}}$ & $\alpha_{\mathrm{DE}}$ & $\alpha_{\mathrm{SF}}$ & $\alpha_{\mathrm{BN}}$ \\
\hline $5.1 \mathrm{e}-8$ & 0.032 & $1.3 e-8$ & $1.5 e-9$ & 0.027 & $1.6 \mathrm{e}-7$ & 0.090 \\
$(5.5 e-5)$ & $(0.039)$ & $(2.9 \mathrm{e}-5)$ & $(7.0 \mathrm{e}-6)$ & $(0.047)$ & $(1.6 \mathrm{e}-4)$ & $(0.074)$
\end{tabular}

NOTES: this table presents maximum likelihood estimates of the $\beta$ and $\alpha$ parameters for the baseline specification. Estimates of $\Sigma$ are omitted to save space. Standard errors are in parentheses and are estimated by numerical computation of the Hessian matrix at the maximum likelihood estimates. A (**) denotes significance at 5 percent. See text for further details. 
TABLE 3

Goodness of Fit: Including Effects of Aggregate Shocks

\begin{tabular}{|c|c|c|c|c|c|}
\hline \multirow[b]{2}{*}{ City } & \multirow[b]{2}{*}{ Case } & \multirow{2}{*}{$\begin{array}{c}\text { Implied } \\
\text { Volatility }\end{array}$} & \multicolumn{3}{|c|}{----Pairwise Correlations---- } \\
\hline & & & Mean & Stan Dev & Corr w/Data \\
\hline \multirow{2}{*}{$\begin{array}{l}\text { Average Over } \\
\text { Sample Cities }\end{array}$} & Data & $5.26 \%$ & 0.151 & 0.384 & 1 \\
\hline & Fitted & $5.03 \%$ & 0.163 & 0.254 & 0.602 \\
\hline \multirow[t]{2}{*}{ New York } & Data & $3.32 \%$ & 0.224 & 0.403 & 1 \\
\hline & Fitted & $3.20 \%$ & 0.202 & 0.272 & 0.597 \\
\hline \multirow[t]{2}{*}{ Los Angeles } & Data & $4.66 \%$ & 0.150 & 0.377 & 1 \\
\hline & Fitted & $4.53 \%$ & 0.154 & 0.245 & 0.561 \\
\hline \multirow[t]{2}{*}{ Chicago } & Data & $4.21 \%$ & 0.107 & 0.384 & 1 \\
\hline & Fitted & $4.36 \%$ & 0.143 & 0.258 & 0.671 \\
\hline \multirow[t]{2}{*}{ Philadelphia } & Data & $3.81 \%$ & 0.079 & 0.352 & 1 \\
\hline & Fitted & $4.19 \%$ & 0.129 & 0.201 & 0.499 \\
\hline \multirow[t]{2}{*}{ Detroit } & Data & $7.86 \%$ & 0.168 & 0.415 & 1 \\
\hline & Fitted & $7.46 \%$ & 0.177 & 0.319 & 0.807 \\
\hline \multirow[t]{2}{*}{ San Francisco } & Data & $7.11 \%$ & 0.155 & 0.369 & 1 \\
\hline & Fitted & $5.23 \%$ & 0.134 & 0.212 & 0.546 \\
\hline \multirow[t]{2}{*}{ Boston } & Data & $5.82 \%$ & 0.172 & 0.393 & 1 \\
\hline & Fitted & $6.27 \%$ & 0.204 & 0.274 & 0.536 \\
\hline
\end{tabular}

NOTES: This table presents evidence on the fit of the baseline model. Rows marked "Data" use the covariance matrix of the raw data, while rows marked "Fitted" use the covariance matrix of the fitted model, including the effects of aggregate shocks. The second column reports the standard deviation of city employment implied by equation (24) in the text. The next two columns show the mean and standard deviation of within-city pairwise correlations, while the final column reports the correlation between the fitted and observed pairwise correlations. See the text for additional information. 
TABLE 4

Goodness of Fit: Excluding Aggregate Shocks

\begin{tabular}{|c|c|c|c|c|c|}
\hline \multirow[b]{2}{*}{ City } & \multirow[b]{2}{*}{ Case } & \multirow{2}{*}{$\begin{array}{c}\text { Implied } \\
\text { Volatility }\end{array}$} & \multicolumn{3}{|c|}{---Pairwise Correlations---- } \\
\hline & & & Mean & Stan Dev & Corr w/Data \\
\hline \multirow{2}{*}{$\begin{array}{l}\text { Average Over } \\
\text { Sample Cities }\end{array}$} & Data & $4.05 \%$ & 0.113 & 0.410 & 1 \\
\hline & Fitted & $3.74 \%$ & 0.133 & 0.157 & 0.211 \\
\hline \multirow[t]{2}{*}{ New York } & Data & $2.61 \%$ & 0.175 & 0.415 & 1 \\
\hline & Fitted & $2.45 \%$ & 0.155 & 0.185 & 0.249 \\
\hline \multirow{2}{*}{ Los Angeles } & Data & $3.84 \%$ & 0.131 & 0.418 & 1 \\
\hline & Fitted & $3.67 \%$ & 0.141 & 0.170 & 0.227 \\
\hline \multirow[t]{2}{*}{ Chicago } & Data & $2.67 \%$ & 0.051 & 0.403 & 1 \\
\hline & Fitted & $2.89 \%$ & 0.102 & 0.126 & 0.232 \\
\hline \multirow{2}{*}{ Philadelphia } & Data & $2.81 \%$ & 0.026 & 0.390 & 1 \\
\hline & Fitted & $2.99 \%$ & 0.095 & 0.111 & 0.070 \\
\hline \multirow[t]{2}{*}{ Detroit } & Data & $4.89 \%$ & 0.108 & 0.406 & 1 \\
\hline & Fitted & $4.20 \%$ & 0.114 & 0.137 & 0.277 \\
\hline \multirow[t]{2}{*}{ San Francisco } & Data & $6.56 \%$ & 0.137 & 0.401 & 1 \\
\hline & Fitted & $4.46 \%$ & 0.114 & 0.135 & 0.238 \\
\hline \multirow[t]{2}{*}{ Boston } & Data & $4.97 \%$ & 0.162 & 0.435 & 1 \\
\hline & Fitted & $5.49 \%$ & 0.209 & 0.238 & 0.184 \\
\hline
\end{tabular}

NOTES: This table presents evidence on the fit of the baseline model. Rows marked "Data" use the covariance matrix of the residuals from regressing the data on aggregate shocks, while rows marked "Fitted" use the covariance matrix of the fitted model, excluding the effects of aggregate shocks. The second column reports the standard deviation of city employment implied by equation (24) in the text. The next two columns show the mean and standard deviation of within-city pairwise correlations, while the final column reports the correlation between the fitted and observed pairwise correlations. See the text for additional information. 
TABLE 5

Variance Decomposition, Baseline Specification

-\% of Local Employment Volatility Due to Component--

\begin{tabular}{|c|c|c|c|c|c|c|c|c|}
\hline Component & NY & LA & $\mathrm{CH}$ & $\mathrm{PH}$ & $\mathrm{DE}$ & SF & $\mathrm{BN}$ & $A \cup$ \\
\hline Macro Shocks & 41.4 & 34.2 & 56.1 & 49.1 & 68.2 & 27.3 & 23.2 & 42.8 \\
\hline Diagonal Terms & 10.0 & 8.9 & 6.2 & 16.0 & 9.1 & 21.8 & 16.2 & 12. \\
\hline Cost Links (COST) & 1.6 & 2.4 & 2.1 & 2.1 & 0.9 & 1.7 & 1.6 & 1. \\
\hline Demand Links (DEM) & 1.6 & 2.3 & 3.0 & 2.5 & 1.7 & 3.4 & 2.6 & \\
\hline $\begin{array}{l}\text { Symmetric Local } \\
\text { Spillovers (SIZE) }\end{array}$ & 15.3 & 20.5 & 13.2 & 13.5 & 7.7 & 32.0 & 24.5 & 18 \\
\hline $\begin{array}{ll}\text { Asymmetric } & \text { Local } \\
\text { Spillovers } & \text { (CITY) }\end{array}$ & 28.2 & 13.3 & 15.9 & 15.1 & 6.9 & 10.7 & 7.6 & 14 \\
\hline $\begin{array}{l}\text { Local Common } \\
\text { Shocks (COMMON) }\end{array}$ & 0.0 & 14.8 & 0.0 & 0.0 & 4.5 & 0.0 & 21.8 & \\
\hline Interactions & 1.9 & 3.6 & 3.3 & 1.7 & 1.0 & 3.1 & 2.5 & 2. \\
\hline
\end{tabular}

NOTES: This table decomposes the city-level employment variance implied by the fitted model into parts due to aggregate shocks, symmetric and asymmetric local spillovers, and other elements. The second through eighth columns present the decomposition for individual cities; the final column averages over sample cities. See the text for further information. 
TABLE 6

Transport Costs and Nontraded Goods

$$
\begin{aligned}
\mathrm{y}_{\mathrm{t}}=\mu+\mathrm{G} * \mathrm{a}_{\mathrm{t}}+\mathrm{A} * \varepsilon_{\mathrm{t}}+\mathrm{v}_{\mathrm{t}} \\
\mathrm{A}=\mathrm{ID}+\beta_{1} * \operatorname{COST}+\beta_{2} * \mathrm{DEM}+\beta_{3} * \mathrm{SIZE} \\
+\beta_{5} * \operatorname{COSTLO}+\beta_{6} * \mathrm{DEMLO}+\beta_{7} * \text { SIZELO } \\
\Omega=\beta_{4} * \operatorname{CITY}+\alpha * \text { COMMON }+\beta_{8} * \text { CITYLO }+\beta_{9} * \text { LOCAL }
\end{aligned}
$$

\begin{tabular}{cccc}
$\beta_{1}$ & $\beta_{2}$ & $\beta_{3}$ & $\beta_{4}$ \\
\hline 0.193 & 0.342 & 1.881 & 0.883 \\
$(0.205)$ & $(0.253)$ & $* *(0.268)$ & $* *(0.305)$
\end{tabular}

$\begin{array}{ccccc}\beta_{5} & \beta_{6} & \beta_{7} & \beta_{8} & \beta_{9} \\ -0.323 & -0.008 & -5.599 & 5.017 & -0.084 \\ (0.054) & (0.544) & * *(0.735) & * *(0.907) & * *(0.029)\end{array}$

\begin{tabular}{ccccccc}
$\alpha_{N Y}$ & $\alpha_{L A}$ & $\alpha_{C H}$ & $\alpha_{P H}$ & $\alpha_{D E}$ & $\alpha_{S F}$ & $\alpha_{B N}$ \\
\hline $3.7 e-8$ & 0.009 & $1.4 e-10$ & $8.9 e-16$ & $8.3 e-10$ & 0.013 & 0.048 \\
$(3.8 e-5)$ & $(0.013)$ & $(1.60 e-6)$ & $(3.60 e-9)$ & $(4.90 e-6)$ & $(0.019)$ & $(0.037)$
\end{tabular}

NOTES: this table presents maximum likelihood estimates of the $\beta$ and $\alpha$ parameters for the specification allowing for nontradeability. Estimates of $\boldsymbol{\Sigma}$ are omitted to save space. Standard errors are in parentheses and are estimated by numerical computation of the Hessian matrix at the maximum likelihood estimates. A (**) denotes significance at 5 percent. See text for further details. 